\title{
Eisvogel im Palmengarten
}

\author{
Hilke Steinecke \& Winfried Faust
}

\section{Abstract}

The Common Kingfisher, a rather rare bird species, is sometimes observed in the Palmengarten. The species and its habits are described.

\section{Zusammenfassung}

Gelegentlich ist im Palmengarten ein Eisvogel zu beobachten. Am Großen Weiher und am Seerosenbecken geht er auf Fischfang. Erscheinungsbild, Verhalten und Ökologie des Eisvogels werden vorgestellt.

\section{Ein schillernder Gast}

Es ist heutzutage schon eine kleine Sensation bzw. für Naturfreunde eine Freude, einen Eisvogel zu Gesicht zu bekommen. Meist schießt er wie ein stahlblauer Pfeil am Beobachter vorbei, so dass dieser kaum Gelegenheit hat, ihn näher zu betrachten. Auf Frankfurter Stadtgebiet können Eisvögel beispielsweise mit etwas Glück an der Nidda gesichtet werden.

Im Herbst und Winter 2007 war nun auch im Palmengarten mindestens ein Eisvogel regelmäßiger Gast. Auch im benachbarten Botanischen Garten wird gelegentlich ein Eisvogel gesichtet. Besonders in den Morgenstunden, wenn es im Palmengarten noch ganz ruhig ist, konnte man den Vogel aus relativ geringer Entfernung gut beobachten. Er saß auf Bäumen am Wasser und ließ sich gut fotografieren. Gern hielt er sich am Großen Weiher oder am beheizten Wasserbecken am Tropicarium (Seerosenbecken) auf, um auf Fischfang zu gehen. Der geringe Fischbesatz im Seerosenbecken wurde hin und wieder durch kleine Futter-Fische aufgestockt.

\section{Lebensweise}

Der etwas über sperlingsgroße und bis $40 \mathrm{~g}$ schwere Eisvogel (Alcedo atthis) gehört einer eigenen Familie an und wird zur Ordnung der Racken gezählt. Er ist in Deutschland streng geschützt und war hier 1973 Vogel des Jahres. Die Schweiz kürte ihn erst 2006 zum Jahresvogel. Aufgrund der milderen Winter, der Verbesserung der Wasserqualität vieler Flüsse und Bäche sowie Renaturierungsmaßnahmen haben sich seine Bestände in den letzten Jahren mancherorts etwas erholt. Der Eisvogel ist an seiner charakteristischen Gefiederfärbung(saphirblau- er Rücken, orangerote Brust und zwei weiße Flecken am Hals) leicht zu erkennen. Die auffällige Färbung gilt als Warntracht, denn sein Fleisch soll faulig schmecken, weshalb er so gut wie nicht von Greifvögeln angegriffen wird. Die beiden Geschlechter unterscheiden sich kaum voneinander. Das Männchen hat einen schwarzen Schnabel, der an der Unterseite leicht aufgehellt sein kann. Das Weibchen dagegen hat einen orangefarbenen Unterschnabel.

Der Eisvogel ist hoch spezialisiert. Er lebt an stehenden sowie fließenden Gewässern, die immer mal wieder ihren Lauf verändern und deren Ufer anreißen oder an dessen Böschungen Wurzeln ufernaher Bäume freigespült werden. Hier gräbt er sich Höhlen, die ihm als Brutplätze dienen. Die Bruthöhlen sind nur spärlich mit Fischgräten ausgepolstert. Die Eingänge sind an Kotmarkierungen zu erkennen. Das Gelege besteht meist aus sieben Eiern. Der Eisvogel brütet bis zu vier Mal im Jahr, oft werden die nächsten Eier bereits gelegt, wenn die Jungen des vorhergehenden Geleges noch nicht flügge sind. Folglich benötigt ein Eisvogelpärchen unter Umständen gleichzeitig zwei Brutröhren. Zudem leben die Männchen mono- oder bigam. Während das Weibchen die Eier bebrütet, füttert das Männchen die heranwachsenden Jungen. Ein Pärchen kann in einem guten Jahr ohne verregneten Sommer bis zu 20 Junge großziehen. Allerdings ist die Sterblichkeitsrate recht hoch, viele Eisvögel werden nicht älter als zwei Jahre. Durch diese hohe Vermehrungsrate kann eine Population gut auf drastische Veränderungen des Lebensraumes reagieren und sich auch schnell wieder nach einer Katastrophe (z.B. Überschwemmung und Zerstörung der Brut) 
erholen. In den extrem kalten Wintern 1962/63 oder 1995/96 kam es zu starken Verlusten in den Eisvogel-Populationen. Schon nach wenigen Jahren jedoch hatten sich jeweils die Bestände wieder erholt. Es bleibt zu hoffen, dass Eisvögel auch weiterhin geeigneten Lebensraum im Palmengarten finden.

\section{Ein guter Fischfänger}

Ähnlich wie beim Zaunkönig ist der Schwanz des Eisvogels sehr kurz. Zusammen mit seinem kräftigen, spitzen Schnabel verleiht ihm dies torpedoförmige Gestalt, wenn er sich im Sturzflug ins Wasser begibt. Er macht Jagd auf bis zu acht $\mathrm{cm}$ lange Fische. Wichtige Futterfische sind Elritze, Moderlieschen, Rotauge, Ukelei, Flussbarsch, Stichling, Groppe und Bachforelle. Gelegentlich ernährt er sich aber auch von Wasserkäfern, Libellenlarven, Kaulquappen oder Wasserwanzen. Bevor er einen Fisch mit dem Kopf nach vorn verschlingt, schlägt er ihn gegen einen Ast. Hat er einen Fisch am Schwanz gepackt, frisst er ihn nicht selber, sondern verfüttert ihn an die Jungen oder das brütende Weibchen.

Vielleicht entdecken ja auch Sie auf Ihrem nächsten Spaziergang durch den Palmengarten oder entlang eines Baches dieses Juwel unter den heimischen Vögeln.

Abb. 1 (oben): Die Fischjagd am Seerosenbecken neben dem Tropicarium war für den Eisvogel erfolgreich.

Abb. 2 (unten): Der Rücken des Eisvogels, hier auf einer Sumpfzypresse sitzend, leuchtet stahlblau.
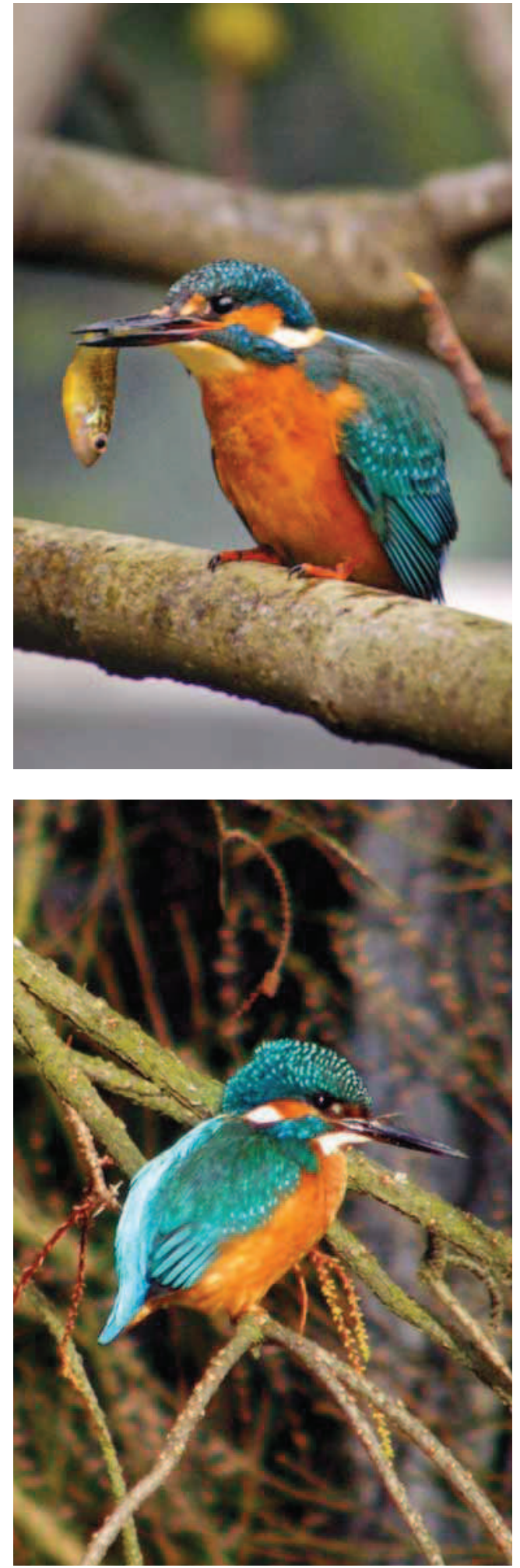